\title{
Not all jellyfish are equal: isotopic evidence for inter- and intraspecific variation in jellyfish trophic ecology
}

Nicholas E.C. Fleming, Chris Harrod, Jason Newton, Jonathan D.R. Houghton

Jellyfish are highly topical within studies of pelagic food-webs and there is a growing realisation that their role is more complex than once thought. Efforts being made to include jellyfish within fisheries and ecosystem models are an important step forward, but our present understanding of their underlying trophic ecology can lead to their oversimplification in these models. Gelatinous zooplankton represent a polyphyletic assemblage spanning $>2,000$ species that inhabit coastal seas to the deep-ocean and employ a wide variety of foraging strategies. Despite this diversity, many contemporary modelling approaches include jellyfish as a single functional group feeding at one or two trophic levels at most. Recent reviews have drawn attention to this issue and highlighted the need for improved communication between biologists and theoreticians if this problem is to be overcome. We used stable isotopes to investigate the trophic ecology of three cooccurring scyphozoan jellyfish species (Aurelia aurita, Cyanea lamarckii and C. capillata) within a temperate, coastal food-web in the NE Atlantic. Using information on individual size, time of year and $\delta^{13} \mathrm{C}$ and $\delta^{15} \mathrm{~N}$ stable isotope values we examined: (1) whether all jellyfish could be considered as a single functional group, or showed distinct inter-specific differences in trophic ecology; (2) Were size-based shifts in trophic position, found previously in A. aurita, a common trait across species?; (3) When considered collectively, did the trophic position of three sympatric species remain constant over time? Differences in $815 \mathrm{~N}$ (trophic position) were evident between all three species, with size-based and temporal shifts in $815 \mathrm{~N}$ apparent in $A$. aurita and C. capillata. The isotopic niche width for all species combined increased throughout the season, reflecting temporal shifts in trophic position and seasonal succession in these gelatinous species. Taken together, these findings support previous assertions that jellyfish require more robust inclusion in marine fisheries or ecosystem models. 
1 Not all jellyfish are equal: isotopic evidence for inter- and intraspecific variation in jellyfish

2 trophic ecology

3

4 Nicholas E. C. Fleming ${ }^{1,2}$, Chris Harrod ${ }^{1,3^{*}}$, Jason Newton ${ }^{4} \&$ Jonathan D.R. Houghton ${ }^{1,2}$

5

6

$7 \quad$ 'School of Biological Sciences, Queen's University Belfast, Medical Biology Centre, 97 Lisburn

8 Road, Belfast BT9 7BL, U.K.

9 2Queen's University Belfast Marine Laboratory, 12-13 The Strand, Portaferry, Co. Down, BT22

10 1PF, U.K.

$11{ }^{3}$ Fish and Stable Isotope Ecology Laboratory, Instituto de Ciencias Naturales Alexander von

12 Humboldt, Universidad de Antofagasta, Avenida Angamos 601, Antofagasta, Chile

$13{ }^{4}$ NERC Life Sciences Mass Spectrometry Facility, Scottish Universities Environmental Research

14 Centre, Scottish Enterprise, Technology Park, East Kilbride G75 0QF, U.K.

15

16

17 * Author for correspondence: chris@harrodlab.net

18

19 
Introduction

22 Jellyfish (here considered as Phylum Cnidaria; Class Scyphozoa) are a conspicuous, yet long23 overlooked component of pelagic marine systems. In recent years the notion of gelatinous 24 species as merely carbon sinks, or trophic dead ends has become largely obsolete (Arai 2005; 25 Hansson \& Norrman 1995) and there is renewed interest in their trophic ecology (Stoner \& 26 Layman 2015; Sweetman et al. 2014). Beyond widely-recognised obligate predators of jellyfish 27 such as leatherback turtles (Houghton et al. 2006), Arai (2005) drew attention to a wide range of 28 opportunistic carnivores such as molluscs, arthropods, reptiles and birds that feed upon gelata 29 episodically. More recently, opportunist scavenging on jellyfish has been observed in the deep30 sea (Sweetman et al. 2014) as well shallower benthic environments (Stoner \& Layman 2015).

31 From a perspective of top-down control, it is also known that the collective prey-consumption 32 rates of gelatinous aggregations can be so high that predation can directly or indirectly control 33 the population size of other zooplanktonic organisms including larval fish (Nielsen et al. 1997; 34 Purcell 1992). Moreover, evidence of sized-based trophic shifts in the moon jellyfish Aurelia 35 aurita (Linnaeus, 1758) (Fleming et al. 2011; Graham \& Kroutil 2001) suggest that jellyfish 36 could themselves exhibit size-associated shifts in trophic ecology, e.g. similar to those shown by 37 fishes (Graham et al. 2007).

Prompted by a growing body of evidence, Pauly et al. (2009) stressed that the functional role of 40 gelatinous taxa requires more robust inclusion in marine fisheries or ecosystem models. At 41 present, such species are typically considered as a single functional group or an 'average' group 42 of animals, feeding on the same prey throughout their life history (Boero et al. 2008; Pauly et al. 
43 2009). Indeed, out of 100 models considered, only $23 \%$ incorporated jellyfish as a distinct

44 functional group (normally feeding at a single trophic level) and only $4 \%$ of models considered

45 them in any greater detail, e.g. feeding at two trophic levels (Pauly et al. 2009). Consequently,

46 seasonal or ontogenetic shifts in diet (Fleming et al. 2011; Graham \& Kroutil 2001), intra-

47 specific differences in prey types (Fancett 1988)) and intra-guild predation (Bayha et al. 2012;

48 Robison 2004; Titelman et al. 2007) are typically over-simplified or disregarded entirely. Pauly

49 et al. (2009) and Doyle et al. (2014) have made a number of suggestions for researchers working

50 with gelatinous species on how to generate data that are useful to theoreticians. These studies

51 highlight the fact that the ecological-modelling community cannot be expected to consider

52 jellyfish in adequate detail, if the data required are not provided by other researchers (Doyle et al.

53 2014). This is a valid point, but until recently many questions surrounding the trophodynamics of

54 gelatinous species appeared intractable, given the spatial and temporal variability of aggregations

55 (Doyle et al. 2007; Houghton et al. 2007), the broad-scale over which they can occur (Doyle et

56 al. 2008) and methodological limitations (Purcell 2009).

58 Within this broad context, the aim of this study was to examine trophic variation in three 59 sympatric jellyfish species (Aurelia aurita (Linnaeus, 1758), Cyanea lamarckii (Péron \& 60 Lesueur, 1810) and C. capillata (Linnaeus, 1758)) in a temperate coastal marine system.

61 Strangford Lough in Northern Ireland was identified as an ideal study system as it supports an 62 annual succession of gelatinous zooplankton species from early May to late August (Fleming et 63 al. 2013). We used stable isotopes $\left(\delta^{13} \mathrm{C}\right.$ and $\left.\delta^{15} \mathrm{~N}\right)$ to consider size-based and temporal shifts in 64 the trophic ecology of the three jellyfish species, both individually and collectively as a dominant 65 large gelatinous zooplankton community. Isotopic approaches have been used widely to examine 
66 the trophic ecology of marine and estuarine systems in general (Peterson \& Fry 1987), and are

67 gathering momentum for the study of gelatinous species (Kogovšek et al. 2014; Nagata et al.

68 2015; Pitt et al. 2008). To provide data that might aid the further inclusion of jellyfish into

69 ecosystem models, our analyses were aligned to examine three specific questions: (1) could all

70 jellyfish be considered as a single functional group or was there evidence for distinct inter-

71 specific differences in trophic ecology?; (2) were size-based shifts in trophic ecology found

72 previously in A. aurita a common trait across species?; and (3) when considered collectively, did

73 the trophic position and isotopic niche of three sympatric species remain constant over time?

75 MATERIALS \& METHODS

76 Collection and processing

77 Strangford Lough (54 $28^{\prime} 20.98^{\prime \prime} \mathrm{N} 5^{\circ} 35^{\prime} 10.60^{\prime \prime} \mathrm{W}$; Northern Ireland) is a large, semi-enclosed 78 coastal embayment $\left(150 \mathrm{~km}^{2}\right)$ that flows into the northern Irish Sea (see Maloy et al. 2013 for a 79 description). Three scyphozoan jellyfish species are persistently present in the lough but their 80 relative abundance varies over time. In May, the community is typically dominated by Aurelia 81 aurita, with an increase in Cyanea lamarckii in early June and Cyanea capillata in July (Fleming 82 et al. 2014). All three species disappear from the water column in the same order from late July 83 onwards (Fleming et al. 2014; Fleming et al. 2013). Medusae of these three jellyfish species were 84 sampled monthly from Strangford Lough (May 2010 to September 2010). Jellyfish were 85 collected near the surface from a small boat using a dip net (mesh size $1 \mathrm{~mm}$ ) for smaller 86 jellyfish and a larger net (5 mm mesh size) for larger individuals. Sampling was conducted in a 87 non-random manner, as our aim was to collect sufficient individuals to allow for balanced 88 statistical comparisons (e.g. across months). Unfortunately, owing to temporal variation in the 
89 abundance of the different species, and often challenging weather conditions, it was not possible

90 to ensure a balanced number of samples per species.

92 Filter-feeding bivalves (Mytilus spp.) and grazing gastropods (Littorina saxatilis (Olivi)) were 93 sampled over the study period from intertidal areas adjacent to the jellyfish sampling sites over 94 the same period (Woodland et al. 2012). These species are long-lived, dominant and ubiquitous, 95 providing a measure of isotopic baselines of the pelagic (bivalve) and benthic (gastropods) 96 primary production pathways as suggested by Post (2002) and supported by others (e.g. Mallela $97 \&$ Harrod 2008; Richoux \& Ndhlovu 2014). Furthermore, isotopic turnover rates (expressed as 98 half-life) in the moon jellyfish (Aurelia aurita) recently described by D'Ambra et al. (2014) who 99 estimated a half-life for $\delta^{13} \mathrm{C}$ (10.8 days) and $\delta^{15} \mathrm{~N}$ (9.7 days) are similar to that of Mytilus $\left(\delta^{13} \mathrm{C}\right.$ $100=9$ days; $\delta^{15} \mathrm{~N}=14$ days) (Dubois et al. 2007), suggesting a similar ability to track temporal 101 shifts in baseline isotope values.

\section{Laboratory and SIA analysis}

104 All jellyfish samples were collected and processed immediately to prevent potentially marked 105 effects of freezing and ethanol preservation (Fleming et al. 2011). A. aurita, C. lamarckii and C. 106 capillata were weighed and measured (wet mass: $\pm 1 \mathrm{~g}$; bell diameter: $\pm 1 \mathrm{~cm}$ ), then medusae 107 were rinsed thoroughly in filtered seawater, after which bell (mesoglea) tissues were separated 108 and dried at $60^{\circ} \mathrm{C}$ in a drying oven following Fleming et al. (2011). Samples were ground to a 109 fine powder in an agate mortar and pestle and then weighed into tin cups prior to stable isotope 110 analysis. Preliminary analyses revealed that optimal sample mass for mass spectrometry varied

111 between taxa i.e. A. aurita $\approx 12 \mathrm{mg} ;$ C. lamarckii $\approx 2.4 \mathrm{mg}$, C. capillata $\approx 5.1 \mathrm{mg}$ and other taxa 
$112 \approx 0.8 \mathrm{mg}$ ). Samples were analysed for $\delta^{13} \mathrm{C}, \delta^{15} \mathrm{~N}$ and $\mathrm{C}: \mathrm{N}$ at the East Kilbride Node of the

113 Natural Environment Research Council Life Sciences Mass Spectrometry Facility via continuous

114 flow isotope ratio mass spectrometry using an ECS 4010 elemental analyser (Costech, Milan,

115 Italy) interfaced with a Delta XP mass spectrometer (Thermo Electron, Bremen, Germany). The

116 standard deviation of multiple analyses of an internal gelatine standard was $\sim 0.1 \%$ for both

$117 \quad \delta^{13} \mathrm{C}$ and $\delta^{15} \mathrm{~N}$.

118

119 Statistical analysis

120 Prior to analysis, bell mass, bell diameter and stable isotope data were $\log _{10}$-transformed to

121 improve normality and reduce heteroscedasticity $\left(\delta^{13} \mathrm{C}\right.$ data were $\log _{10}+40$ transformed due to

122 their negative values). Recently evidence has emerged that air-drying gelatinous tissue can result

123 in ${ }^{15} \mathrm{~N}$ enrichment in more proteinaceous species (Kogovšek et al. 2014). C:N ratios of the three

124 species were compared and found not to differ $\left(F_{2,120}=1.48, P=0.232\right)$, suggesting that any

125 effect of air-drying would be consistent across species. We used various statistical approaches to

126 characterise and compare the trophic ecology (inter-specific, intra-specific and community) of

127 the jellyfish species.

128

129 Permutational multivariate analysis of variance (PERMANOVA) (Anderson 2001; Anderson et

130 al. 2008) in PRIMER 6.1.12 (Clarke \& Gorley 2006; Clarke \& Warwick 2001) was used to

131 examine variation in the location of centroids of $\log _{-10}$ transformed $\delta^{15} \mathrm{~N}-\delta^{13} \mathrm{C}$ data, based on a

132 Euclidean similarity matrix ( $\mathrm{n}_{\text {permutations }}=9$ 999). PERMANOVA was used to examine variation

133 in bell $\delta^{15} \mathrm{~N}$ and $\delta^{13} \mathrm{C}$ values by species (inter-specific variation) and sample month (intra-

134 specific variation). Here, it is assumed that where $\delta^{15} \mathrm{~N}-\delta^{13} \mathrm{C}$ centroids overlap (i.e. are not 
135 significantly different), then trophic ecology is similar e.g. between species or month. As some

136 small $(\mathrm{n} \leq 3)$ sample sizes were recorded for species across the different months (C. capillata in

137 May; A. aurita and C. lamarckii in August), it was not possible to make a balanced two-way

138 analysis for the entire study period. A full two-way PERMANOVA examining isotopic variation

139 associated with Species and Month (and the Species x Month interaction) was conducted for

140 June and July only. One-way PERMANOVA was used to compare variation within species

141 across months.

142

143 Two-way PERMANOVA was used to examine whether $\delta^{15} \mathrm{~N}-\delta^{13} \mathrm{C}$ values from baseline

144 indicators associated with the pelagic and benthic pathways varied either between functional

145 groups or over time (survey month). We also conducted a similar univariate two-way

146 PERMANOVA comparing temporal shifts in $\delta^{15} \mathrm{~N}$ data from the two functional groups in order

147 to examine whether shifts in jellyfish $\delta^{15} \mathrm{~N}$ were related to changes at the base of the food web or

148 in apparent jellyfish trophic level.

149

150 As jellyfish are often considered as a single functional group, we examined how an indicator of

151 community level trophic position varied across the survey period by pooling $\delta^{15} \mathrm{~N}$ data from all

152 three jellyfish species and conducting a univariate PERMANOVA with month as a fixed 153 independent factor.

155 We used the SIBER procedure (Stable Isotope Bayesian Ellipses in R) within the R package

156 SIAR (Jackson et al. 2011) to examine variation in jellyfish isotopic niche space. This approach

157 relies on the concept that multiple stable isotope ratios measured from consumers represent niche 
158 dimensions, e.g. variation in $\delta^{13} \mathrm{C}$ reflects use of different energy sources, or habitats, while $\delta^{15} \mathrm{~N}$

159 provides information on the trophic level at which a consumer feeds (Peterson \& Fry 1987). This

160 so called 'isotopic niche' or ' $\delta$-space' (Newsome et al. 2007) is thought to reflect the trophic

161 niche of groups of consumers (Bearhop et al. 2004; Fink et al. 2012; Layman et al. 2007), where

162 more isotopic variation reflects a larger consumer isotopic niche, assuming that spatial or

163 temporal variation in baseline isotopic values is considered. Here we use Bayesian Standard Area

164 Ellipses $\left(\mathrm{SEA}_{\mathrm{B}}\right)$, as the use of Bayesian inference allows the incorporation of uncertainty such as

165 small sample sizes (Jackson et al. 2011). This iterative approach uses Monte Carlo Markov-

166 Chain simulation to construct ellipses characterising isotopic variation that provide a robust

167 indicator of isotopic niche width. We used this technique to characterise temporal variation in the

168 trophic niche of the three jellyfish species, as well as overlap between species. We also examined

169 temporal variation in $\mathrm{SEA}_{\mathrm{B}}$ values calculated for the jellyfish community as a whole (i.e. all

170 three species of jellyfish combined). In order to examine the differences in isotopic niche area

$171\left(\mathrm{SEA}_{\mathrm{B}}\right)$ between different consumer groups, we calculated probabilities from posterior

172 distributions (based on 100,000 draws) of the parameters of model $M$ given the prior data $D$

$173(\operatorname{Pr}(M \mid D))$. These maximum likelihood comparisons provide direct probabilities of differences

174 rather than the traditional frequentist test of a null-hypothesis. In order to differentiate these

175 comparisons, maximum-likelihood based probabilities are reported here as percentages.

176

177 In stable isotope studies, consumer trophic position is typically estimated from $\delta^{15} \mathrm{~N}$ data, which

178 are corrected for baseline variation and trophic fractionation (Post 2002). Although we had

179 reliable data on pelagic and benthic $\delta^{15} \mathrm{~N}$ baselines (see above), information on jellyfish trophic

180 enrichment factors (TEFs) is extremely limited. D'Ambra et al. (2014) recently provided TEFS 
181 for A. aurita, in what represents the only experimental estimate of jellyfish trophic fractionation

182 in the literature. The mean \pm SD TEFs estimated by D'Ambra et al. for A. aurita $\left(\Delta^{13} \mathrm{C}=4.3 \pm\right.$ $1830.2 \% ; \Delta^{15} \mathrm{~N}=0.1 \pm 0.2 \%$ ) are very unusual and contrast markedly with the average TEFS more 184 commonly seen in the literature (e.g. Post (2002): $\Delta{ }^{13} \mathrm{C}=0.4 \pm 1.3 \%$; $\Delta{ }^{15} \mathrm{~N}=3.4 \pm 1 \%$;

185 McCutchan et al. (2003) $\left(\Delta^{13} \mathrm{C}=0.5 \pm 1.3 \%, \Delta^{15} \mathrm{~N}=2.3 \pm 1.5 \%\right.$ ). As use of the jellyfish specific

186 TEFs provided by D'Ambra (2014) resulted in unfeasibly high trophic positions for the jellyfish

187 species, including A. aurita, we did not make direct estimates of trophic position, but provide 188 indirect estimates by presenting $\delta^{15} \mathrm{~N}$ data.

189

190 Finally normal linear least-squares regression was used to examine how $\log _{-10}$ transformed stable 191 isotope values $\left(\delta^{13} \mathrm{C}\right.$ data were $\log _{10}+40$ transformed) varied with individual size (bell wet mass 192 and diameter).

193

194 Statistical analyses were conducted using routines in PRIMER-E 6 (Clarke \& Gorley 2006) and 195 SYSTAT 13.1 (SYSTAT Software Inc 2009). SIBER analyses (Jackson et al. 2011) were 196 conducted using SIAR (Parnell et al. 2010) in R version 3.1.2 (R Development Core Team 197 2014). An alpha level of 0.05 is used throughout to indicate statistical significance. 


\section{RESULTS}

200

201 Comparisons of baseline indicator (filter feeding and grazing molluscs) $\delta^{15} \mathrm{~N}-\delta^{13} \mathrm{C}$ values across the study period using two-way PERMANOVA showed strong evidence of isotopic differences 203

\section{Inter-specific variation} between the two functional groups (Pseudo- $\left.\mathrm{F}_{1,108}=82.44, \mathrm{P}=0.0001\right)$, but less evidence for marked temporal differences (Month: Pseudo- $\mathrm{F}_{2,108}=2.64, \mathrm{P}=0.06$ ). There was no evidence for a significant interaction between these two factors $\left(\right.$ Pseudo- $\left.\mathrm{F}_{2,108}=0.04, \mathrm{P}=0.99\right)$, indicating that the isotopic differences between the two functional groups were maintained over time.

We also examined $\delta^{15} \mathrm{~N}$ values from filter feeding and grazing molluscs as they provide a reference for measurements of consumer trophic position relative to the base of the food web. Baseline $\delta^{15} \mathrm{~N}$ values differed between the two functional groups $\left(\right.$ Pseudo- $\mathrm{F}_{1,108}=59.57, \mathrm{P}=$ 0.0001 ) with benthic grazers (mean $\pm \mathrm{SD} \delta^{15} \mathrm{~N}=11.2 \pm 1.08, \mathrm{n}=58$ ) being ${ }^{15} \mathrm{~N}$ enriched by 1.5 $\%$ relative to filter feeding bivalves (bivalve $=9.7 \pm 0.7, \mathrm{n}=56$ ) but were consistent across the study period (PERMANOVA on $\log _{10}$-transformed $\delta^{15} \mathrm{~N}$ data; Month: Pseudo- $\mathrm{F}_{2,108}=0.48, \mathrm{P}=$ 0.725). The lack of an interaction between the two factors (Month x Functional Group: Pseudo$\left.F_{2,108}=0.087, P=0.91\right)$ indicated that the differences in $\delta^{15} \mathrm{~N}$ between the two functional groups remained constant over time.

A total of 122 medusae were collected from the surface of the water column comprising Aurelia aurita $(n=43)$, Cyanea lamarckii $(n=36)$ and C. capillata $(n=43)$. Data collected across the 
222 entire study for the three jellyfish species (Fig. 1) showed considerable intraspecific variation

223 and apparent isotopic overlap between the species. However, when $\delta^{15} \mathrm{~N}$ and $\delta^{13} \mathrm{C}$ data for

224 individual species were compared over time, differences became apparent (Table 1; Fig. 2).

225

226 A full two-way PERMANOVA comparing the influence of survey month and species was only 227 possible for all three species in the months of June and July when medusae of all species were 228 present. The analysis of $\log _{10}$-transformed data revealed that $\delta^{15} \mathrm{~N}-\delta^{13} \mathrm{C}$ centroid location varied 229 significantly between the three jellyfish species $\left(\right.$ Pseudo- $\left.\mathrm{F}_{2,71}=5.01, \mathrm{P}=0.006\right)$ and survey 230 month (Pseudo- $\mathrm{F}_{1,71}=5.1, \mathrm{P}=0.02$ ). However, there was no interaction between species and 231 survey month $\left(\mathrm{F}_{2,71}=0.25, \mathrm{P}=0.82\right)$ indicating that temporal shifts in $\delta^{13} \mathrm{C}-\delta^{15} \mathrm{~N}$ isotope values 232 were similar across the three scyphozoan species in June and July. Pairwise comparisons showed 233 that A. aurita were isotopically distinct from both Cyanea species in June (C. lamarckii $\mathrm{P} \leq$ 2340.0043 ; C. capillata $\mathrm{P}=0.02)$, and from C. lamarckii in July $(\mathrm{P}=0.03)$. The $\delta^{15} \mathrm{~N}-\delta^{13} \mathrm{C}$ centroids 235 of the two Cyanea species overlapped during these months (June: $\mathrm{P}=0.89$; July: $\mathrm{P}=0.43$ ). 236

237 Next, we considered inter-specific differences in isotopic niche width (Fig. 3). Between-species 238 comparisons (data pooled from all months) showed that C. capillata had the largest mean (95\% 239 credibility limits) isotopic niche width of $6.90(4.95-9.03) \%{ }^{2}$, compared to A. aurita (4.94 $\left.240(3.55-6.46) \% 0^{2}\right)$ or C. lamarckii $\left(5.49(3.84-7.32) \% 0^{2}\right)$. Maximum-likelihood pairwise 241 comparisons indicated a borderline probability (Probability $(\mathrm{P})=94 \%$ ) that across the entire 242 study the isotopic niche width of C. capillata was larger than that of A. aurita. There was no 243 statistical support $(\mathrm{P}=85 \%)$ for differences between C. capillata, and its congeneric $C$. 
244 lamarckii. There was a $67 \%$ probability of differences in isotopic niche width size between $A$.

245 aurita and C. lamarckii.

246

247 Intra-specific variation

248

249 Although A. aurita were captured in each of the survey months (Fig. 2), sufficient samples for 250 analysis were not recorded in August $(\mathrm{n}=2)$, and statistical comparisons here are limited to the 251 period May-July (See Table 1 for sample sizes). During this period, the location of A. aurita $252 \delta^{15} \mathrm{~N}-\delta^{13} \mathrm{C}$ centroids varied significantly (One-way PERMANOVA Pseudo- $\mathrm{F}_{2,38}=15.19, \mathrm{P}=$ 253 0.0001), indicating that $A$. aurita underwent an isotopic shift over the study period. Pairwise tests 254 showed that $\delta^{15} \mathrm{~N}-\delta^{13} \mathrm{C}$ centroids shifted between May and both June $(\mathrm{t}=4.49, \mathrm{P}=0.0002)$ and 255 July $(\mathrm{t}=4.77, \mathrm{P}=0.0001) . \delta^{15} \mathrm{~N}-\delta^{13} \mathrm{C}$ values overlapped in June and July $(\mathrm{t}=1.6, \mathrm{P}=0.12)$. The 256 difference between May and the other months reflected enrichment in ${ }^{13} \mathrm{C}$ and to a lesser degree $257{ }^{15} \mathrm{~N}$ from May to the later months.

258

259 Sample sizes in C. lamarckii were relatively low throughout the study, with large numbers only

260 being encountered in June (Table 1). C. lamarckii showed significant temporal shifts in the 261 location of the $\delta^{15} \mathrm{~N}-\delta^{13} \mathrm{C}$ centroids (May - July: Pseudo- $\mathrm{F}_{2,31}=15.46, \mathrm{P}=0.0001$ ). Pairwise tests 262 revealed that centroids differed between May and both June $(\mathrm{t}=5.15, \mathrm{P}=0.0002)$ and July $(\mathrm{t}=$ $2636.58, \mathrm{P}=0.001)$, but overlapped between June and July $(\mathrm{t}=0.63, \mathrm{P}=0.56)$. Isotopically, $C$. 264 lamarckii became increasingly ${ }^{13} \mathrm{C}$ and ${ }^{15} \mathrm{~N}$ enriched over the survey period (Fig. 2, Table 1). 265 
266 Only two C. capillata were available for analysis in May, but in the following months, $\delta^{15} \mathrm{~N}-\delta^{13} \mathrm{C}$

267 centroids for this species changed significantly (June-August: Pseudo- $\mathrm{F}_{2,38}=4.44, \mathrm{P}=0.008$ ).

268 Pairwise tests indicated that this shift was relatively gradual, with isotopic overlap in June and 269 July $(\mathrm{t}=1.87, \mathrm{P}=0.06)$ and July-August $(\mathrm{t}=1.22, \mathrm{P}=0.22)$. Isotopic differences were most 270 marked at the extremes of the collection period: June - August $(t=2.79, P=0.003)$.

272 Bayesian estimates of isotopic niche width $\left(\mathrm{SEA}_{\mathrm{B}}\right)$ showed significant variation within species 273 during the study period (Table 3 \& Fig. 3). Pairwise comparisons showed that A. aurita mean 274 isotopic niche width was lower in May relative to other months (Table 3, Fig. 3), with a $95 \%$ 275 probability of a difference from June and a $98 \%$ probability of a difference from July. The 276 isotopic niche width of $C$. lamarckii was reduced in May relative to June $(\mathrm{P}=99 \%)$ and July (P $277=96 \%$ ), but there were no obvious differences in isotopic niche width in June and July (P=46 $278 \%$ \%. C. capillata was not recorded in sufficient numbers in May to allow analyses, but showed a 279 similar isotopic niche width through the June - August period (P range $50-60 \%$ ). 280

281 Both $A$. aurita and C. capillata showed positive linear relationships between $\log _{10}$-transformed $282 \delta^{13} \mathrm{C}$ and wet mass ((Table 2, Fig. 4: A. aurita $\mathrm{F}_{1,41}=26.9, \mathrm{R}^{2}=0.40, \mathrm{P}<0.001 ;$ C. capillata $\mathrm{F}_{1,41}$ $\left.283=16.1, \mathrm{R}^{2}=0.28, \mathrm{P}<0.001\right)$ and bell diameter $\left(\right.$ A. aurita $\mathrm{F}_{1,41}=26.3, \mathrm{R}^{2}=0.39, \mathrm{P}<0.001 ; C$. 284 capillata $\mathrm{F}_{1,41}=19.1, \mathrm{R}^{2}=0.32, \mathrm{P}<0.001$ ), indicating a shift in dietary source with size in these 285 species. However, there was no evidence for any such relationship in C. lamarckii for wet mass $286\left(\mathrm{~F}_{1,35}=0.71, \mathrm{R}^{2}=0.02, \mathrm{P}=0.405\right)$ or bell diameter $\left(\mathrm{F}_{1,35}=0.85, \mathrm{R}^{2}=0.02, \mathrm{P}=0.363\right)$, 287 indicating that individuals of all sizes assimilated carbon from a similar range of sources. $\delta^{15} \mathrm{~N}$ 288 increased with size (Fig. 4 \& Table 2$)$ in both $A$. aurita $\left(\log _{10}\right.$-transformed wet mass $\mathrm{F}_{1,41}=48.8$, 
$289 \mathrm{R}^{2}=0.54, \mathrm{P}<0.001$; bell diameter $\mathrm{F}_{1,41}=46.2, \mathrm{R}^{2}=0.53, \mathrm{P}=<0.001$ ) and C. capillata (wet 290 mass $\mathrm{F}_{1,41}=22.1, \mathrm{R}^{2}=0.35, \mathrm{P}=<0.001$; bell diameter $\left.\mathrm{F}_{1,41}=22.0, \mathrm{R}^{2}=0.34, \mathrm{P}<0.001\right)$. In all 291 cases, the slope of the $\log _{10}-\log _{10}$ relationship was $<1$ (Table 2). As in the case of $\delta^{13} \mathrm{C}, C$. 292 lamarckii showed no evidence of any size-based shift in $\delta^{15} \mathrm{~N}$ (wet mass $=\mathrm{F}_{1,35}=1.50, \mathrm{R}^{2}=0.04$, $293 \mathrm{P}=0.229$; bell diameter $\mathrm{F}_{1,35}=2.4, \mathrm{R}^{2}=0.06, \mathrm{P}=0.131$ ).

\section{Variation at a whole community level}

As baseline $\delta^{15} \mathrm{~N}$ values were consistent over time (see 'Baseline variation' above), we were able to use $\delta^{15} \mathrm{~N}$ as an indirect indicator of changes in whole community apparent trophic position over time in the absence of reliable TEFs. $\delta^{15} \mathrm{~N}$ values for the dominant gelatinous zooplankton community (All GZ) as measured here, varied over the study period (One-way univariate PERMANOVA Pseudo- $\mathrm{F}_{3,119}=36.9, \mathrm{P}=0.0001$; Fig. 2), and showed relative increases in apparent trophic position $\left(\delta^{15} \mathrm{~N}\right)$ over time. Pairwise tests showed $\delta^{15} \mathrm{~N}$ in May was lower than in all other months (June, $\mathrm{t}=6.2, \mathrm{P}=0.0001 ;$ July, $\mathrm{t}=10.6, \mathrm{P}=0.0001$; August, $\mathrm{t}=13.3, \mathrm{P}=$ 0.0001). June $\delta^{15} \mathrm{~N}$ values were higher than May, but lower than subsequent months (May, $\mathrm{t}=$ $6.2, \mathrm{P}=0.0001 ;$ July, $\mathrm{t}=3.1, \mathrm{P}=0.0027$; August, $\mathrm{t}=4.4, \mathrm{P}=0.002$ ). There was no measurable difference in whole community $\delta^{15} \mathrm{~N}$ values in July and August $(\mathrm{t}=1.9, \mathrm{P}=0.07$; Fig. 2).

307 We also examined temporal variation in the community isotopic niche width by pooling values 308 from the three jellyfish species (See all GZ values in Fig. 3). Mean (95\% credibility limits) 309 jellyfish isotopic niche width in May was lower than in June, July or August ( $\mathrm{P}=100 \%$ in all 310 cases). However, isotopic niche for the combined jellyfish species began to change in position 311 and width as the season progressed with an increase in isotopic niche $\left(\% 0^{2} 95 \%\right.$ credibility limits $)$ 
312 from May $=2.05(1.31-2.89)$ to Aug $=5.72(3.49-8.3)$, suggesting a broader trophic niche in

313 the latter months (P July $>$ June $=54 \%$; P August $>$ June $=76 \%$; P August $>$ July $=70 \%$ ).

314

315 


\section{Discussion}

317 Pauly et al. (2009) described jellyfish as arguably the most important predators in the sea. There

318 is little ambiguity in this statement which, in part, prompted the present study. There is no doubt

319 that the potential expansion of jellyfish in highly depleted oceans is a matter of grave concern

320 (Lynam et al. 2006; Purcell et al. 2007), and an underlying knowledge of how jellyfish function

321 within marine systems is required, so that long-standing trends in populations and communities

322 can be teased apart from shifts in ecosystem structure. Stable isotope analysis offers a powerful

323 biochemical approach to the estimation of trophic and dietary composition of individuals through

324 to communities (Bearhop et al. 2004; Bolnick et al. 2003) and the results presented here support

325 the idea that jellyfish play a more complex trophic role than once envisaged.

326

327 Consistency in baseline isotope values

328 Variation in $\delta^{15} \mathrm{~N}-\delta^{13} \mathrm{C}$ values measured from baseline indicators of the pelagic (filter feeding 329 bivalve) and benthic (grazing gastropod) energy pathways was driven by functional group rather 330 than survey month. This indicates that any temporal differences observed in jellyfish isotope 331 values and the measures derived from them (i.e. isotopic niche space), reflected changes in 332 jellyfish diet over time rather than shifts at the base of the food web.

334 Inter-specific differences in trophic ecology

335 At the whole study level, isotopic differences were evident between the three jellyfish species in 336 terms of $\delta^{15} \mathrm{~N}$ and $\delta^{13} \mathrm{C}$, with post-hoc comparisons highlighting differences between $A$. aurita 337 and both Cyanea species in June, and with C. lamarckii in July. Conversely, the Cyanea species 338 showed isotopic overlap during June and July. Comparisons of isotopic niche width showed that 
339 differences were most marked between A. aurita v C. capillata. Taken together, these results

340 suggest differences in jellyfish behaviour and their capacity to capture and ingest a range of prey

341 items between these two genera (Figs $2 \& 3$ ).

342

343 Typically, scyphozoan jellyfish encounter rather than detect and pursue prey and use both

344 'passive ambush' and 'feeding current' feeding strategies with direct interception and filtering

345 through tentacles being used in both cases (Kiørboe 2011). Feeding currents are generated by

346 pulsation of the bell which varies in shape and size between species, with slower velocities

347 normally associated with smaller individuals (Costello \& Colin 1994; Costello \& Colin 1995;

348 Kiørboe 2011). Depending on the escape velocities of putative prey, differences in feeding

349 current velocity between different jellyfish species might lead to different prey being captured 350 and ingested; however, further work is required to link trophic position with morphological

351 characteristics in an empirical manner.

352

353 A. aurita have a much reduced capture surface (shorter tentacles) compared with the Cyanea spp.

354 Heeger \& Möller (1987) found that the majority of prey capture by A. aurita in Kiel Harbour, N

355 Germany, occurred on the tentacles as opposed to the subumbrellar surface, so this reduced

356 capture area may account for the low trophic position and narrowest niche width of this species 357 in the present study.

359 Although they differ in terms of maximum individual size, the congenerics $C$. lamarckii and $C$. 360 capillata have similarities in both nematocyst complement (Ostman \& Hydman 1997; Shostak 361 1995) and morphology (Holst \& Laakmann 2013). Previous studies have reported predation of 
362 C. capillata on A. aurita medusae, therefore it is possible that the differences observed with $A$.

363 aurita may be a symptom of intra-guild predation by the larger C. capillata (e.g. Hansson 1997;

364 Purcell 2003; Titelman et al. 2007).

365

366 The isotopic variation found in this study suggests niche partitioning and represents a host of

367 differences in morphology, bell pulsation strength, prey capture techniques and nematocyst

368 composition that enable differential prey capture (Bayha \& Dawson 2010; Costello \& Colin

369 1994; Peach \& Pitt 2005). Therefore, caution must clearly be taken to avoid over-simplification

370 of jellyfish in ecosystem models. In a broader context, as gelatinous zooplankton span $>2,000$

371 species (Condon et al. 2012), occupying habitats ranging from the deep ocean through to shallow

372 water near-shore environments, the inclusion of an 'average' jellyfish in such models is likely to

373 underestimate the collective impact in terms of energy flow or consumption of prey (Pauly et al.

374 2009).

375

376 Intra-specific differences in trophic ecology

377 A. aurita and C. capillata shifted their use of both energy source $\left(\delta^{13} \mathrm{C}\right)$ and trophic position

$378\left(\delta^{15} \mathrm{~N}\right)$ with increasing body size, independent of time (Fig. 4). This suggests that different sized

379 jellyfish medusae, present in the water column at the same time and with access to the same prey

380 field, feed at different positions in the food web (Fleming et al. 2011; Graham \& Kroutil 2001).

381 The simultaneous presence of different sized medusae appears to be a consistent trait across a

382 range of species at temperate latitudes (Houghton et al. 2007), suggesting that jellyfish

383 reproductive cohorts are often poorly defined with a marked overlap within given seasons. $C$.

384 lamarckii, however did not exhibit a size-based shift in trophic position with increasing body 
385 size. This most likely reflects the comparatively narrow size range of the medusae sampled (3.5 -

$38620 \mathrm{~cm}$ ), with the species rarely exceeding a bell diameter of $30 \mathrm{~cm}$ (Russell 1970). By

387 comparison, C. capillata medusae spanned a far broader size range $(6-85 \mathrm{~cm})$ allowing size

388 related shifts in diet to be more easily identified. There are also size related differences in

389 toxicity; although C. lamarckii is as venomous as C. capillata (Helmholz et al. 2007), as both

390 species increase in size, so too do the size of their nematocysts (Ostman \& Hydman 1997). These

391 findings suggest that body size in jellyfish may, to some extent, underpin their capacity to feed at

392 multiple trophic levels through ontogeny. There are some clear exceptions to this rule e.g. small

393 gelatinous species ( $<12 \mathrm{~cm}$ bell diameter) such as box jellyfish Chironex fleckeri and Carukia

394 barnesi have extraordinarily powerful stings that enable them to capture relatively large prey

395 such as larval and small fishes (Carrette et al. 2002; Kintner et al. 2005; Underwood \& Seymour 396 2007).

398 The trophic position of the jellyfish community over time

399 When considered as a whole, the $\delta^{15} \mathrm{~N}$ values of the scyphozoan jellyfish community in

400 Strangford Lough increased as the season progressed (Fig. 2), even though baseline levels

401 remained constant. This increase in $\delta^{15} \mathrm{~N}$ was unlikely to be a result of a general increase in size

402 of jellyfish over time, as a range of sizes of each species were collected and analysed each month

403 (see Appendix S1). Given that $\delta^{15} \mathrm{~N}$ baselines were constant across the study period, this

404 indicates that trophic position increased over time. In terms of isotopic niche width, there was an

405 interesting dissimilarity between the start of the season (May) and the following months (June,

406 July and August), suggesting a shift to a broader dietary niche in the latter months (Fig. 3). This

407 increased resource utilisation is consistent with previous studies that suggested jellyfish dietary 
408 niches are extremely broad, with species operating as generalists (Dawson \& Martin 2001; Ishii

409 \& Båmstedt 1998; Schneider \& Behrends 1998) feeding opportunistically across a range of 410 plankton (Båmstedt et al. 1997; Titelman et al. 2007). Therefore, our data suggest that a different 411 and possibly constrained resource pool is being exploited at the beginning of the jellyfish 412 season'. There are of course environmental factors such as temperature which could have an 413 effect on N metabolism \& excretion in jellyfish (Morand et al. 1987; Nemazie et al. 1993) and 414 temperature can have a significant effect on isotopic turnover times in a range of taxa (see 415 Thomas \& Crowther 2015). The temperature increase in Strangford Lough over the course of the 416 study was modest (from $8.7-14.2^{\circ} \mathrm{C}$ ) but cannot be discounted as a possible influence on 417 isotopic variation over time. The sequential change in species composition seen in Strangford 418 Lough could, in part, be the result of intra-guild predation (Bayha et al. 2012; Robison 2004; 419 Titelman et al. 2007), which may also contribute to the observed broadening in isotopic niche. 420 Additionally, the collective increase in trophic position over time may reflect species succession 421 in the lough with a general shift from an $A$. aurita dominated in system in May through to a $C$. 422 capillata dominated system in August (Fleming et al. 2014). Most likely our results reflect 423 interplay of these two scenarios but highlight the problems associated with assuming that 424 different jellyfish species occupy a single trophic position or ecological niche (Boero et al. 2008; 425 Pauly et al. 2009). 426

427 Interspecific and temporal variation in consumer isotopes values can be put into deeper 428 ecological context through the use of models to estimate trophic position (Post 2002) and 429 consumption patterns (Phillips et al. 2014). However, the use of these models requires reliable 430 estimates of trophic enrichment factors. We welcome the recent TEF estimates made by 
431 D'Ambra et al. (2014) for Aurelia sp., however, we found that the use of their TEFS resulted in

432 unfeasibly high trophic positions for the Aurelia and other jellyfish in our system. For example, 433 using Post's (2002) basic model for tropic position resulted in a mean jellyfish trophic position 434 of 17, with the baseline provided by our mean Mytilus $\delta^{15} \mathrm{~N}$ values. As such, realistic estimates of 435 jellyfish trophic level and consumption made using tools requiring accurate TEFS (e.g. mixing 436 models) remain problematic. We therefore call for more experimental work to characterise 437 jellyfish TEFs.

438

439 Conclusions

440 All species showed temporal shifts in their location in $\delta^{15} \mathrm{~N}-\delta^{13} \mathrm{C}$ space across the study. Given

441 the lack of marked changes at the base of the food web, this suggests that the three jellyfish

442 species consumed different prey across the study period. Size-based shifts in $\delta^{13} \mathrm{C}$ and $\delta^{15} \mathrm{~N}$

443 values were evident in two of the three jellyfish species examined here, leading to an inference

444 that variation in body size in some way drives variation in the trophic ecology of a particular 445 species. Distinct differences in $\delta^{13} \mathrm{C}$ and $\delta^{15} \mathrm{~N}$ values were found within and between species, 446 with evidence of niche segregation between A. aurita and the two Cyanea species. Niche width 447 for all species combined increased considerably throughout the season, reflecting interplay of 448 possible intra-guild predation, temporal shifts in $\delta^{13} \mathrm{C}$ and $\delta^{15} \mathrm{~N}$ values and the seasonal 449 succession in gelatinous species.

451 Taken together, these lines of evidence reinforce the idea that scyphozoan jellyfish require more 452 elegant inclusion in ecosystem or fisheries-based models. The salient point here is that jellyfish 453 should not be averaged or defined as a single amorphous group with little reference to temporal 454 and allometric shifts in individual species or gelatinous communities alike. 


\section{Acknowledgements}

457

458 We are grateful to Phillip Johnston from Queen's University, Belfast Marine Laboratory

459 (QUML) for boat support and sample collection. Thanks also go to Eoin Bleakney, Claire

460 Armstrong, Debbie Baird-Bower and Natalie McCullagh for help with sample processing.

461 
Anderson MJ. 2001. A new method for non-parametric multivariate analysis of variance. Austral Ecology 26:32-46.

Anderson MJ, Gorley RN, and Clarke KR. 2008. PERMANOVA+ for PRIMER: Guide to Software and Statistical Methods. Plymouth, UK: PRIMER-R.

Arai MN. 2005. Predation on pelagic coelenterates: a review. Journal of the Marine Biological Association of the United Kingdom 85:523-536.

Båmstedt U, Ishii H, and Martlnussen MB. 1997. Is the scyphomedusa Cyanea capillata (1.) dependent on gelatinous prey for its early development? Sarsia 82:269-273.

Bayha KM, and Dawson MN. 2010. New family of allomorphic jellyfishes, Drymonematidae (Scyphozoa, Discomedusae), emphasizes evolution in the functional morphology and trophic ecology of gelatinous zooplankton. The Biological Bulletin 219:249-267.

Bayha KM, Graham WM, Higgins III JE, and Fletcher HA. 2012. Predation potential of the jellyfish Drymonema larsoni Bayha \& Dawson (Scyphozoa: Drymonematidae) on the moon jellyfish Aurelia sp. in the northern Gulf of Mexico. Hydrobiologia 690:189-197.

Bearhop S, Adams CE, Waldron S, Fuller RA, and Macleod H. 2004. Determining trophic niche width: a novel approach using stable isotope analysis. Journal of Applied Ecology 73:1007-1012.

Boero F, Bouillon J, Gravili C, Miglietta MP, Parsons T, and Piraino S. 2008. Gelatinous plankton: irregularities rule the world (sometimes). Marine Ecology Progress Series 356:299-310.

Bolnick DI, Svanbäck R, Fordyce JA, Yang LH, Davis JM, Hulsey CD, and Forister ML. 2003. The ecology of individuals: Incidence and implications of individual specialization. American Naturalist 161:1-28.

Carrette T, Alderslade P, and Seymour J. 2002. Nematocyst ratio and prey in two Australian cubomedusans, Chironex fleckeri and Chiropsalmus sp. Toxicon 40:1547-1551.

Clarke KR, and Gorley RN. 2006. PRIMER v6: User Manual/Tutorial. Plymouth, UK: PRIMER-E.

Clarke KR, and Warwick RM. 2001. Change in marine communities: an approach to statistical analysis and interpretation, 2nd edition. Plymouth, UK: Primer-E.

Condon RH, Graham WM, Duarte CM, Pitt KA, Lucas CH, Haddock SHD, Sutherland KR, Robinson KL, Dawson MN, Decker MB, Mills CE, Purcell JE, Malej A, Mianzan H, Uye S-I, Gelcich S, and Madin LP. 2012. Questioning the rise of gelatinous zooplankton in the World's oceans. BioScience 62:160-169.

Costello JH, and Colin SP. 1994. Morphology, fluid motion and predation by the scyphomedusa Aurelia aurita. Marine Biology 121:327-334.

Costello JH, and Colin SP. 1995. Flow and feeding by swimming scyphomedusae. Marine Biology 124:399-406.

D'Ambra I, Carmichael R, and Graham W. 2014. Determination of $\delta^{13} \mathrm{C}$ and $\delta^{15} \mathrm{~N}$ and trophic fractionation in jellyfish: implications for food web ecology. Marine Biology 161:473480.

Dawson MN, and Martin LE. 2001. Geographic variation and ecological adaptation in Aurelia (Scyphozoa, Semaeostomeae): some implications from molecular phylogenetics. Hydrobiologia 451:259-273. 
507

508

509

510

511

512

513

514

515

516

517

518

519

520

521

522

523

524

525

526

527

528

529

530

531

532

533

534

535

536

537

538

539

540

541

542

543

544

545

546

547

548

549

550

551

Doyle T, Houghton J, Buckley S, Hays G, and Davenport J. 2007. The broad-scale distribution of five jellyfish species across a temperate coastal environment. Hydrobiologia 579:2939.

Doyle TK, De Haas H, Cotton D, Dorschel B, Cummins V, Houghton JDR, Davenport J, and Hays GC. 2008. Widespread occurrence of the jellyfish Pelagia noctiluca in Irish coastal and shelf waters. Journal of Plankton Research 30:963-968.

Doyle TK, Hays GC, Harrod C, and Houghton JDR. 2014. Ecological and Societal Benefits of Jellyfish. In: Lucas $\mathrm{CH}$, and Pitt KA, eds. Jellyfish blooms. Germany: Springer Science+Business Media.

Dubois S, Jean-Louis B, Bertrand B, and Lefebvre S. 2007. Isotope trophic-step fractionation of suspension-feeding species: Implications for food partitioning in coastal ecosystems. Journal of Experimental Marine Biology and Ecology 351:121-128.

Fancett MS. 1988. Diet and prey selectivity of scyphomedusae from Port Phillip Bay, Australia. Marine Biology 98:503-509.

Fink P, Reichwald ES, Harrod C, and Rossberg AG. 2012. Determining trophic niche width: An experimental test of the stable isotope approach. Oikos 121:1985-1994.

Fleming N, Houghton J, Magill C, and Harrod C. 2011. Preservation methods alter stable isotope values in gelatinous zooplankton: implications for interpreting trophic ecology. Marine Biology 158:2141-2146.

Fleming NEC, Harrod C, Griffin DC, Newton J, and Houghton JDR. 2014. Scyphozoan jellyfish provide short-term reproductive habitat for hyperiid amphipods in a temperate near-shore environment. Marine Ecology Progress Series 510:229-240.

Fleming NEC, Harrod C, and Houghton JDR. 2013. Identifying potentially harmful jellyfish blooms using shoreline surveys. Aquaculture Environment Interactions 4:263-272.

Graham B, Grubbs D, Holland K, and Popp B. 2007. A rapid ontogenetic shift in the diet of juvenile yellowfin tuna from Hawaii. Marine Biology 150:647-658.

Graham WM, and Kroutil RM. 2001. Size-based prey selectivity and dietary shifts in the jellyfish, Aurelia aurita. Journal of Plankton Research 23:67-74.

Hansson LJ. 1997. Capture and digestion of the scyphozoan jellyfish Aurelia aurita by Cyanea capillata and prey response to predator contact. Journal of Plankton Research 19:195208.

Hansson LJ, and Norrman B. 1995. Release of dissolved organic carbon (DOC) by the scyphozoan jellyfish Aurelia aurita and its potential influence on the production of planktonic bacteria. Marine Biology 121:527-532.

Heeger T, and Möller H. 1987. Ultrastructural observations on prey capture and digestion in the scyphomedusa Aurelia aurita. Marine Biology 96:391-400.

Helmholz H, Ruhnau C, Schütt C, and Prange A. 2007. Comparative study on the cell toxicity and enzymatic activity of two northern scyphozoan species Cyanea capillata (L.) and Cyanea lamarckii (Péron \& Léslieur). Toxicon 50:53-64.

Holst S, and Laakmann S. 2013. Morphological and molecular discrimination of two closely related jellyfish species, Cyanea capillata and C. lamarckii (Cnidaria, Scyphozoa), from the northeast Atlantic. Journal of Plankton Research.

Houghton JDR, Doyle TK, Davenport J, Lilley MKS, Wilson RP, and Hays GC. 2007. Stranding events provide indirect insights into the seasonality and persistence of jellyfish medusae (Cnidaria: Scyphozoa). Hydrobiologia 589:1-13. 
552

Houghton JDR, Doyle TK, Wilson MW, Davenport J, and Hays GC. 2006. Jellyfish aggregations and leatherback turtle foraging patterns in a temperate coastal environment. Ecology 87:1967-1972.

Ishii H, and Båmstedt U. 1998. Food regulation of growth and maturation in a natural population of Aurelia aurita (L.). Journal of Plankton Research 20:805-816.

Jackson AL, Inger R, Parnell AC, and Bearhop S. 2011. Comparing isotopic niche widths among and within communities: SIBER - Stable Isotope Bayesian Ellipses in R. Journal of Animal Ecology 80:595-602.

Kintner AH, Seymour JE, and Edwards SL. 2005. Variation in lethality and effects of two Australian chirodropid jellyfish venoms in fish. Toxicon 46:699-708.

Kiørboe T. 2011. How zooplankton feed: mechanisms, traits and trade-offs. Biological Reviews $86: 311-339$.

Kogovšek T, Tinta T, Klun K, and Malej A. 2014. Jellyfish biochemical composition: importance of standardised sample processing. Marine Ecology Progress Series 510:275288.

Layman CA, Arrington DA, Montaña CG, and Post DM. 2007. Can stable isotope ratios provide for community-wide measures of trophic structure. Ecology 88:42-48.

Lynam CP, Gibbons MJ, Axelsen BE, Sparks CAJ, Coetzee J, Heywood BG, and Brierley AS. 2006. Jellyfish overtake fish in a heavily fished ecosystem. Current Biology 16:R492R493.

Mallela J, and Harrod C. 2008. $\delta^{13} \mathrm{C}$ and $\delta^{15} \mathrm{~N}$ reveal significant differences in the coastal foodwebs of the seas surrounding Trinidad and Tobago. Marine Ecology Progress Series 368:41-51.

Maloy A, Nelle P, Culloty S, Slater J, and Harrod C. 2013. Identifying trophic variation in a marine suspension feeder: DNA- and stable isotope-based dietary analysis in Mytilus spp. Marine Biology 160:479-490.

McCutchan JH, Lewis WM, Kendall C, and McGrath CC. 2003. Variation in trophic shift for stable isotope ratios of carbon, nitrogen, and sulfur. Oikos 102:378-390.

Morand P, Carre C, and Biggs DC. 1987. Feeding and metabolism of the jellyfish Pelagia noctiluca (scyphomedusae, semaeostomae). Journal of Plankton Research 9:651-665.

Nagata RM, Moreira MZ, Pimentel CR, and Morandini AC. 2015. Food web characterization based on $\delta^{15} \mathrm{~N}$ and $\delta^{13} \mathrm{C}$ reveals isotopic niche partitioning between fish and jellyfish in a relatively pristine ecosystem. Marine Ecology Progress Series 519:13-27.

Nemazie DA, Purcell JE, and Glibert PM. 1993. Ammonium excretion by gelationous zooplankton and their contribution to the ammonium requirements of microplankton in Chesapeake Bay. Marine Biology 116:451-458.

Newsome SD, Martinez del Rio C, Bearhop S, and Phillips DL. 2007. A niche for isotopic ecology. Frontiers in Ecology and the Environment 5:429-436.

Nielsen AS, Pedersen AW, and Riisgård HU. 1997. Implications of density driven currents for interaction between jellyfish (Aurelia aurita) and zooplankton in a Danish fjord. Sarsia 82:297-305.

Ostman C, and Hydman J. 1997. Nematocyst analysis of Cyanea capillata and Cyanea lamarckii (Scyphozoa, Cnidaria). Scientia Marina 61:313-334.

Pauly D, Graham W, Libralato S, Morissette L, and Deng Palomares M. 2009. Jellyfish in ecosystems, online databases, and ecosystem models. Hydrobiologia 616:67-85. 
597

598

599

600

601

602

603

604

605

606

607

608

609

610

611

612

613

614

615

616

617

618

619

620

621

622

623

624

625

626

627

628

629

630

631

632

633

634

635

636

637

638

639

640

Peach MB, and Pitt KA. 2005. Morphology of the nematocysts of the medusae of two scyphozoans, Catostylus mosaicus and Phyllorhiza punctata (Rhizostomeae): implications for capture of prey. Invertebrate Biology 124:98-108.

Peterson BJ, and Fry B. 1987. Stable isotopes in ecosystem studies. Annual Review of Ecology and Systematics 18:293-320.

Phillips DL, Inger R, Bearhop S, Jackson AL, Moore JW, Parnell AC, Semmens BX, and Ward EJ. 2014. Best practices for use of stable isotope mixing models in food web studies. Canadian Journal Of Zoology.

Pitt KA, Clement A-L, Connolly RM, and Thibault-Botha D. 2008. Predation by jellyfish on large and emergent zooplankton: Implications for benthic-pelagic coupling. Estuarine, Coastal and Shelf Science 76:827-833.

Post DM. 2002. Using stable isotopes to estimate trophic position: models, methods, and assumptions. Ecology 83:703-718.

Purcell JE. 1992. Effects of predation by the scyphomedusan Chrysaora quinquecirrha on zooplankton populations in Chesapeake Bay, USA. Marine Ecology Progress Series 87:65-76.

Purcell JE. 2003. Predation on zooplankton by large jellyfish, Aurelia labiata, Cyanea capillata and Aequorea aequorea, in Prince William Sound, Alaska. Marine Ecology Progress Series 246:137-152.

Purcell JE. 2009. Extension of methods for jellyfish and ctenophore trophic ecology to largescale research. Hydrobiologia 616:23-50.

Purcell JE, Uye S, and Lo W. 2007. Anthropogenic causes of jellyfish blooms and their direct consequences for humans: a review. Marine Ecology Progress Series 350:153-174.

R Development Core Team. 2014. $R$ : A language and environment for statistical computing. Vienna, Austria: R Foundation for Statistical Computing.

Richoux NB, and Ndhlovu RT. 2014. Temporal variability in the isotopic niches of rocky shore grazers and suspension-feeders. Marine Ecology DOI: 10.1111/maec.12200.

Robison BH. 2004. Deep pelagic biology. Journal of Experimental Marine Biology and Ecology 300:253-272.

Russell FS. 1970. The medusae of the British Isles II. Cambridge: Cambridge University Press.

Schneider G, and Behrends G. 1998. Top-down control in a neritic plankton system by Aurelia aurita medusae - a summary. Ophelia 48:71-82.

Shostak S. 1995. Scyphozoa nematocysts: Distribution of nematocyst-types by species. Accessed 5th November 2012. http://www.pitt.edu/ sshostak/cnidocyst_database/scyph.html.

Stoner EW, and Layman CA. 2015. Bristle worms attack: benthic jellyfish are not trophic dead ends. Frontiers in Ecology and the Environment 13:226-227.

Sweetman AK, Smith CR, Dale T, and Jones DOB. 2014. Rapid scavenging of jellyfish carcasses reveals the importance of gelatinous material to deep-sea food webs. Proceedings of the Royal Society B: Biological Sciences 281.

SYSTAT Software Inc. 2009. SYSTAT® 13.1 Richmond, CA, USA.

Thomas SM, and Crowther TW. 2015. Predicting rates of isotopic turnover across the animal kingdom: a synthesis of existing data. Journal of Animal Ecology 84:861-870.

Titelman J, Gandon L, Goarant A, and Nilsen T. 2007. Intraguild predatory interactions between the jellyfish Cyanea capillata and Aurelia aurita. Marine Biology 152:745-756. 
641 Underwood AH, and Seymour JE. 2007. Venom ontogeny, diet and morphology in Carukia 642 barnesi, a species of Australian box jellyfish that causes Irukandji syndrome. Toxicon 643 49:1073-1082.

644 Woodland R, Magnan P, Glémet H, Rodríguez M, and Cabana G. 2012. Variability and 645 directionality of temporal changes in $\delta^{13} \mathrm{C}$ and $\delta^{15} \mathrm{~N}$ of aquatic invertebrate primary 646 consumers. Oecologia 169:199-209.

647 
651 Figure 1: Variation in $\delta^{13} \mathrm{C}$ and $\delta^{15} \mathrm{~N}$ shown in three species of jellyfish over the whole study 652 period. (See Table 1 for summary statistics).

653

654 Figure 2: Box-whisker plots showing variation in $\delta^{13} \mathrm{C}$ (upper panel) and $\delta^{15} \mathrm{~N}$ (lower panel) in 655 the three jellyfish species, and within the dominant GZ community (GZ; all three species

656 combined) over the study period. See Table 1 for sample sizes and other summary statistics. NB:

657 Baseline $\delta^{15} \mathrm{~N}$ values remained constant over this period, indicating that the increase in $\delta^{15} \mathrm{~N}$

658 values reflected a shift in trophic position rather than seasonal shifts at the base of the foodweb.

659 Boxes show inter-quartile range, and the bold horizontal bar indicates the median value.

660 Whiskers reflect values $1.5 \mathrm{x}$ the interquartile range.

661

662 Figure 3: Variation in isotopic niche width (SEAB) between species (A. a = A. aurita; C. $1=C$.

663 lamarckii; C. $\mathrm{c}=$ C. capillata)) and within the dominant GZ community (GZ; all three species

664 combined) sampled over the survey period. Boxes represent the 50, 75 and $95 \%$ Bayesian

665 credibility intervals estimated from 100,000 draws. Samples marked with *included less than 10

666 individuals (see Parnell et al. 2010). See Table 3 for statistical comparisons.

667

668 Figure 4: Variation in bell $\delta^{13} \mathrm{C}(\mathrm{A} \& \mathrm{~B})$ and $\delta^{15} \mathrm{~N}(\mathrm{C} \& \mathrm{D})$ with bell diameter (A \& C) and wet 669 mass (B \& D). Note use of logarithmic scale on $\mathrm{x}$-axes.

670

671

672

673 


\section{Table $\mathbf{1}$ (on next page)}

Summary statistics

Table 1: Summary statistics for bell stable isotope and C: $\mathrm{N}$ ratios. 


\begin{tabular}{|c|c|c|c|c|}
\hline Species & $n$ & $\delta^{13} \mathrm{C}( \pm \mathrm{SD}) \%$ & $\delta^{15} \mathrm{~N}( \pm \mathrm{SD}) \%$ & $C: N( \pm$ SD $)$ \\
\hline Aurelia aurita May & 16 & $-20.3(0.5)$ & $8.5(1.1)$ & $3.8(0.1)$ \\
\hline Aurelia aurita June & 18 & $-18.2(0.5)$ & $10.3(1.5)$ & $3.5(0.4)$ \\
\hline Aurelia aurita July & 9 & $-18.1(0.7)$ & $11.5(1.5)$ & $3.5(0.4)$ \\
\hline Aurelia aurita August & 2 & $-17.3(0.1)$ & $11.8(1.7)$ & $3.7(0.1)$ \\
\hline Overall mean $A$. aurita & 43 & $-19.0(1.2)$ & $9.7(1.6)$ & $3.6(0.2)$ \\
\hline Cyanea lamarckii May & 7 & $-21.4(0.2)$ & $8.6(0.6)$ & $3.9(0.1)$ \\
\hline Cyanea lamarckii June & 21 & $-19.5(0.7)$ & $11.5(1.5)$ & $3.7(0.4)$ \\
\hline Cyanea lamarckii July & 5 & $-19.4(0.8)$ & $12.1(1.3)$ & $3.7(0.3)$ \\
\hline Cyanea lamarckii Aug & 3 & $-19.2(0.8)$ & $11.5(0.8)$ & $3.7(0.2)$ \\
\hline Overall mean C. lamarckii & 36 & $-19.8(1.0)$ & $11.0(1.8)$ & $3.7(0.3)$ \\
\hline Cyanea capillata May & 2 & $-21.4(0.1)$ & $7.7(0.1)$ & $3.8(0.1)$ \\
\hline Cyanea capillata June & 13 & $-19.5(1.2)$ & $11.0(2.1)$ & $3.6(0.4)$ \\
\hline Cyanea capillata July & 14 & $-19.4(1.1)$ & $12.8(1.3)$ & $3.6(0.2)$ \\
\hline Cyanea capillata Aug & 16 & $-18.7(1.6)$ & $13.3(1.1)$ & $3.5(0.3)$ \\
\hline Overall mean $C$. capillata & 43 & $-19.7(1.3)$ & $12.4(1.8)$ & $3.6(0.1)$ \\
\hline
\end{tabular}


Table 2 (on next page)

Summary statistics for least squares regressions

Table 2: Summary statistics for least squares regressions examining relationships between individual jellyfish size and bell stable isotope ratios (mass, length and $\delta^{15} \mathrm{~N}$ data $\log _{10}$ transformed, $\delta^{13} \mathrm{C}$ data $\log _{10}+40$ transformed). NB: in all cases slopes were significantly different from 1. 
2

\begin{tabular}{|c|c|c|c|c|c|c|c|}
\hline Species & Isotope & Comparison & Intercept $( \pm \mathrm{SE})$ & Slope ( \pm SE) & $R^{2}$ & $F$ & $\boldsymbol{P}$ \\
\hline A. aurita & $\begin{array}{c}\delta^{13} \mathrm{C} \\
(-21.1 \text { to }-17.2 \% \text { \% }\end{array}$ & $\begin{array}{l}\text { Bell diameter } \\
(6 \text { to } 36 \mathrm{~cm})\end{array}$ & $1.224(0.019)$ & $0.079(0.015)$ & 0.39 & $\mathrm{~F}_{1,41}=26.3$ & $<0.001$ \\
\hline A. aurita & $\begin{array}{c}\delta^{15} \mathrm{~N} \\
(6.7 \text { to } 14.8 \% \text { o }) \\
\end{array}$ & $\begin{array}{l}\text { Bell diameter } \\
(6 \text { to } 36 \mathrm{~cm})\end{array}$ & $0.609(0.056)$ & $0.305(0.045)$ & 0.53 & $\mathrm{~F}_{1,41}=46.2$ & $<0.001$ \\
\hline A. aurita & $\begin{array}{c}\delta^{13} \mathrm{C} \\
(-21.1 \text { to }-17.2 \%)\end{array}$ & $\begin{array}{c}\text { Wet mass } \\
(12-1702 \mathrm{~g})\end{array}$ & $1.256(0.013)$ & $0.029(0.006)$ & 0.40 & $\mathrm{~F}_{1,41}=26.9$ & $<0.001$ \\
\hline A. aurita & $\begin{array}{c}\delta^{15} \mathrm{~N} \\
(6.7 \text { to } 14.8 \% \text { ) } \\
\end{array}$ & $\begin{array}{c}\text { Wet mass } \\
(12-1702 \mathrm{~g})\end{array}$ & $0.730(0.038)$ & $0.111(0.016)$ & 0.54 & $\mathrm{~F}_{1,41}=48.8$ & $<0.001$ \\
\hline C. lamarckii & $\begin{array}{c}\delta^{13} \mathrm{C} \\
(-21.6 \text { to }-18.5 \% \text { \% })\end{array}$ & $\begin{array}{l}\text { Bell diameter } \\
(4 \text { to } 20 \mathrm{~cm})\end{array}$ & $1.287(0.019))$ & $0.018(0.019)$ & 0.02 & $\mathrm{~F}_{1,35}=0.85$ & $=0.363$ \\
\hline C. lamarckii & $\begin{array}{c}\delta^{15} \mathrm{~N} \\
(7.7 \text { to } 15.8 \% \text { ) }\end{array}$ & $\begin{array}{l}\text { Bell diameter } \\
\text { (4 to } 20 \mathrm{~cm})\end{array}$ & $0.939(0.067)$ & $0.103(0.066)$ & 0.06 & $\mathrm{~F}_{1,35}=2.4$ & $=0.131$ \\
\hline C. lamarckii & $\begin{array}{c}\delta^{13} \mathrm{C} \\
(-21.6 \text { to }-18.5 \%)\end{array}$ & $\begin{array}{c}\text { Wet mass } \\
(3 \text { to } 493 \mathrm{~g})\end{array}$ & $1.293(0.013)$ & $0.006(0.007)$ & 0.02 & $\mathrm{~F}_{1,35}=0.71$ & $=0.405$ \\
\hline C. lamarckii & $\begin{array}{c}\delta^{15} \mathrm{~N} \\
(7.7 \text { to } 15.8 \% \text { ) } \\
\end{array}$ & $\begin{array}{c}\text { Wet mass } \\
(3 \text { to } 493 \mathrm{~g})\end{array}$ & $0.985(0.047)$ & $0.030(0.025)$ & 0.04 & $\mathrm{~F}_{1,35}=1.50$ & $=0.229$ \\
\hline C. capillata & $\begin{array}{c}\delta^{13} \mathrm{C} \\
(-21.8 \text { to }-17.2 \% \text { \% })\end{array}$ & $\begin{array}{l}\text { Bell diameter } \\
(6 \text { to } 85 \mathrm{~cm})\end{array}$ & $1.233(0.020)$ & $0.062(0.014)$ & 0.32 & $\mathrm{~F}_{1,41}=19.1$ & $<0.001$ \\
\hline C. capillata & $\begin{array}{c}\delta^{15} \mathrm{~N} \\
(7.6 \text { to } 16.1 \% \text { ) }\end{array}$ & $\begin{array}{l}\text { Bell diameter } \\
(6 \text { to } 85 \mathrm{~cm})\end{array}$ & $0.876(0.046)$ & $0.157(0.034)$ & 0.34 & $F_{1,41}=22.0$ & $<0.001$ \\
\hline C. capillata & $\begin{array}{c}\delta^{13} \mathrm{C} \\
(-21.8 \text { to }-17.2 \% \text { \% })\end{array}$ & $\begin{array}{c}\text { Wet mass } \\
\text { (19 to } 23680 \mathrm{~g} \text { ) }\end{array}$ & $1.259(0.015)$ & $0.020(0.005)$ & 0.28 & $\mathrm{~F}_{1,41}=16.1$ & $<0.001$ \\
\hline C. capillata & $\begin{array}{c}\delta^{15} \mathrm{~N} \\
\text { (7.6 to } 16.1 \%)\end{array}$ & $\begin{array}{c}\text { Wet mass } \\
\text { (19 to } 23680 \mathrm{~g})\end{array}$ & $0.931(0.035)$ & $0.055(0.012)$ & 0.35 & $\mathrm{~F}_{1,41}=22.1$ & $<0.001$ \\
\hline
\end{tabular}


Table 3 (on next page)

Bayesian comparisons of isotopic niche width (SEAB) between different jellyfish species and survey months

Table 3: Table showing results of Bayesian comparisons of isotopic niche width (SEAB) between different jellyfish species and survey months. Probabilities (based on 100,000 draws) that isotopic niche area in Group A is larger than the comparative value in Group B (A>B) are shown. Species codes: $A$. $a=A$. aurita; $C . I=C$. lamarckii; . $C=C$. capillata). Groups marked with * reflect samples sizes $<10$. 


\begin{tabular}{|c|c|c|c|c|c|c|c|c|c|c|}
\hline \multirow[t]{2}{*}{ Group } & & \multicolumn{9}{|c|}{ Group $A$} \\
\hline & & A. $a$ & A. $a$ & A. $a$ & C. $l$ & C. $l$ & C. $l$ & C. $c$ & C. $c$ & C. $c$ \\
\hline & & May & June & July* & May* & June & July* & June & July & August \\
\hline \multirow{6}{*}{ Group B } & A. $a$ June & & - & 0.756 & 0.062 & 0.855 & 0.728 & 0.927 & 0.938 & 0.969 \\
\hline & A. $a$ July* & & & - & 0.029 & 0.540 & 0.496 & 0.697 & 0.703 & 0.775 \\
\hline & C. $l$ June & & & & & - & 0.460 & 0.713 & 0.722 & 0.821 \\
\hline & C. l July* & & & & & & - & 0.683 & 0.688 & 0.754 \\
\hline & C. c June & & & & & & & - & 0.497 & 0.596 \\
\hline & C. $c$ July & & & & & & & & - & 0.609 \\
\hline
\end{tabular}

2 
1

Isotopic variation in 3 species of co-occuring jellyfish

Figure 1: Variation in $\delta^{13} \mathrm{C}$ and $\delta^{15} \mathrm{~N}$ shown in three species of jellyfish over the whole study period. (See Table 1 for summary statistics).

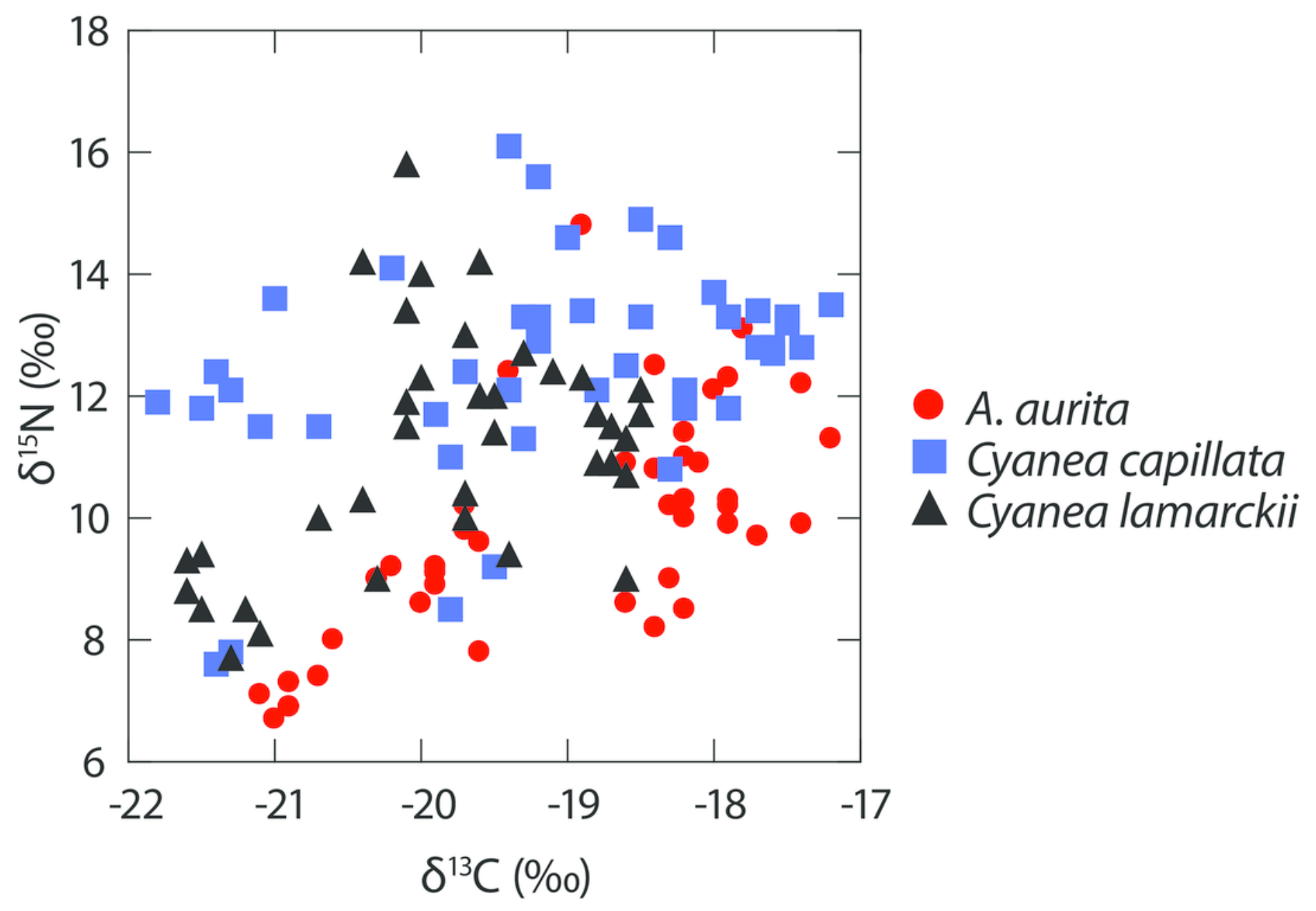


2

Temporal variation in jellyfish $\delta^{13} \mathrm{C}$ and $\delta^{15} \mathrm{~N}$

Figure 2: Box-whisker plots showing variation in $\delta^{13} \mathrm{C}$ (upper panel) and $\delta^{15} \mathrm{~N}$ (lower panel) in the three jellyfish species, and within the dominant gelatinous zooplankton community (GZ; all three species combined) over the study period. See Table 1 for sample sizes and other summary statistics. NB: Baseline $\delta^{15} \mathrm{~N}$ values remained constant over this period, indicating that the increase in $\delta^{15} \mathrm{~N}$ values reflected a shift in trophic position rather than seasonal shifts at the base of the food web. Boxes show inter-quartile range, and the bold horizontal bar indicates the median value. Whiskers reflect values $1.5 \times$ the interquartile range. 


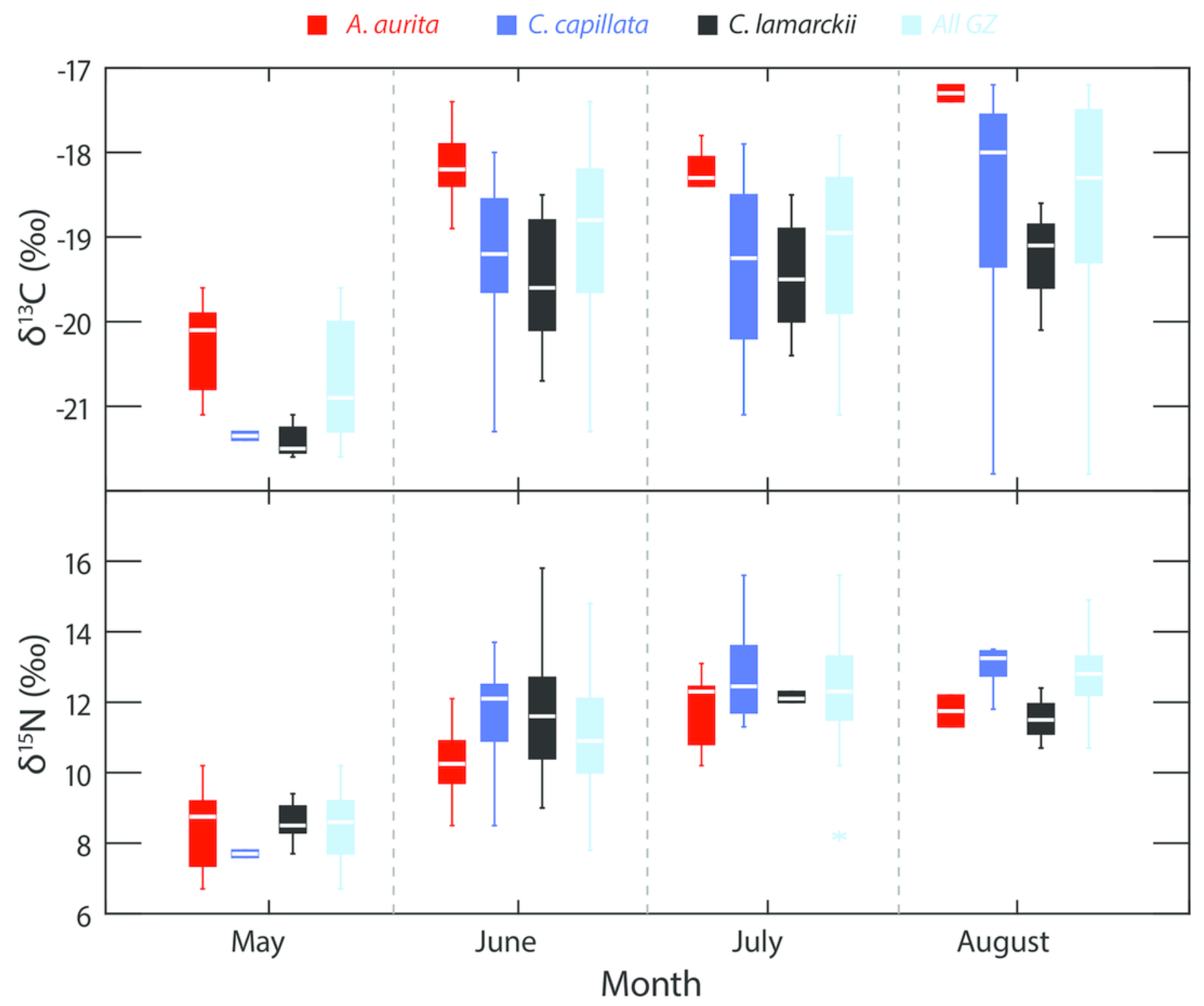




\section{3}

Variation in isotopic niche width $\left(\mathrm{SEA}_{\mathrm{B}}\right)$ between species

Figure 3: Variation in isotopic niche width $\left(\mathrm{SEA}_{B}\right)$ between species $(A . a=A$. aurita; $C . I=C$. lamarckii; $C . c=C$. capillata)) and within the dominant gelatinous zooplankton community (GZ; all three species combined) sampled over the survey period. Boxes represent the 50, 75 and $95 \%$ Bayesian credibility intervals estimated from 100,000 draws. Samples marked with *included less than 10 individuals (see Parnell et al. 2010). See Table 3 for statistical comparisons.

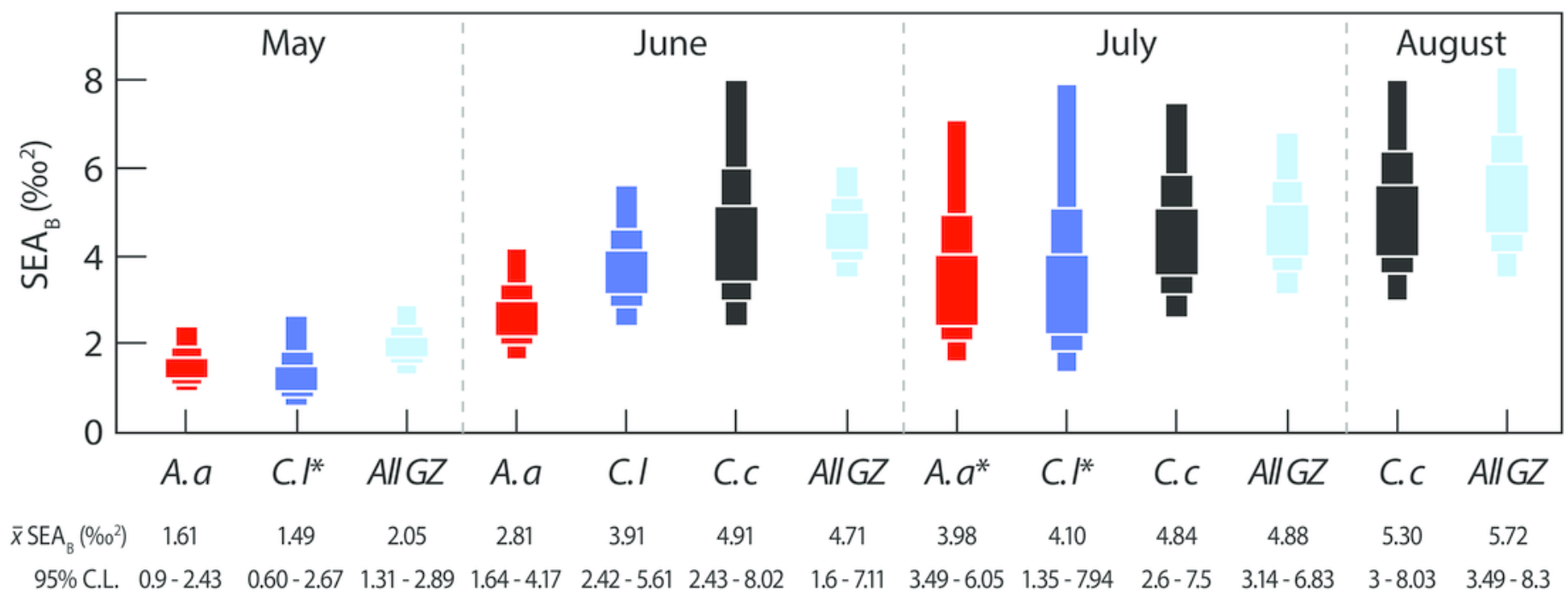


Figure showing isotopic variation with size

Figure 4: Variation in bell $\delta^{13} \mathrm{C}(\mathrm{A} \& \mathrm{~B})$ and $\delta^{15} \mathrm{~N}(C \& D)$ with bell diameter $(A \& C)$ and wet mass $(B \& D)$. Note use of logarithmic scale on $x$-axes.

\section{A. aurita $\square$ C. capillata $\Delta$ C. lamarckii}
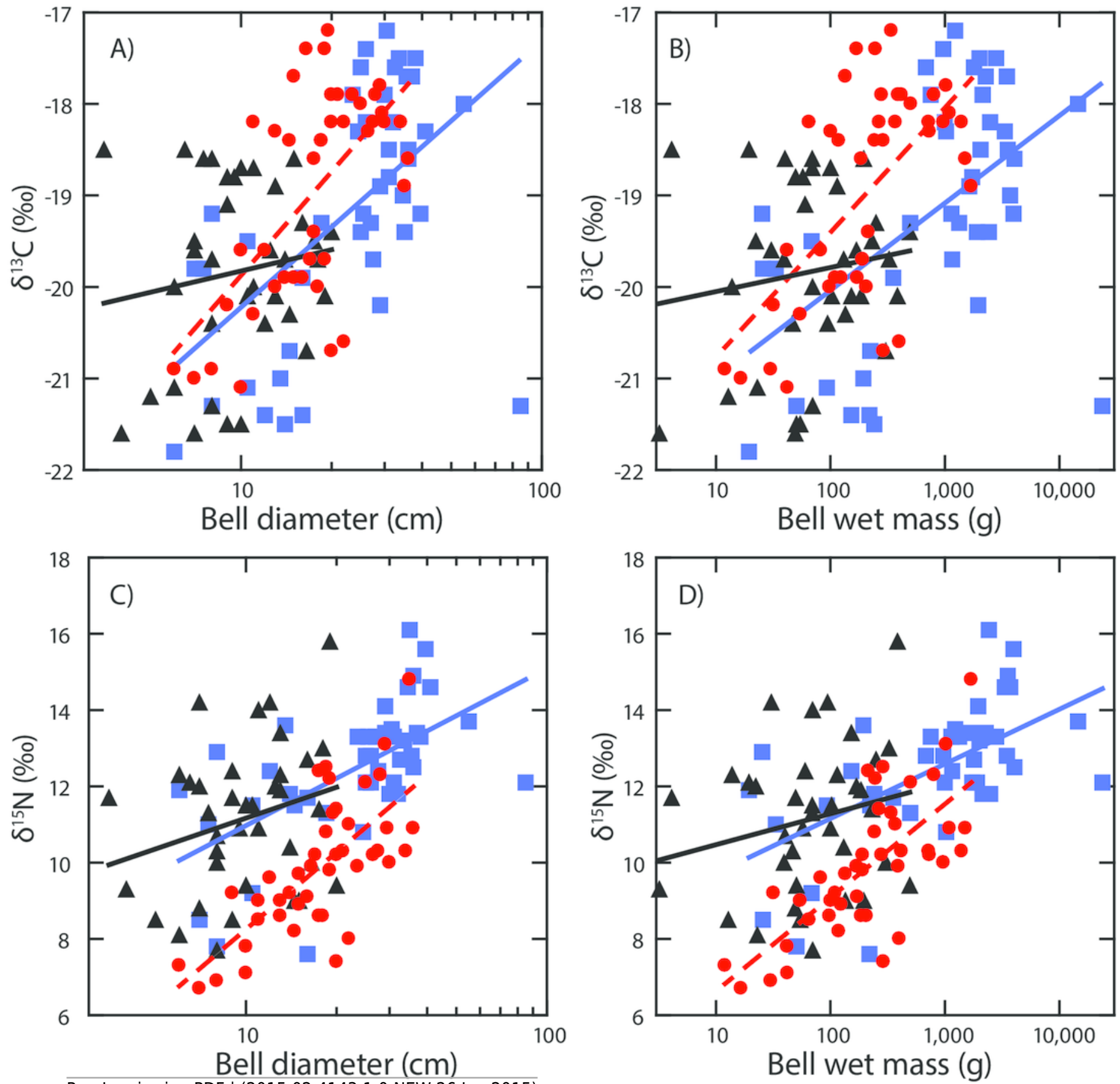